Revue

Revue de l'histoire des religions

de Ihistoire des religions

$1 \mid 2011$

Varia

\title{
Gérard FERREYROLLES, Béatrice GUION, Jean-Louis
} QUANTIN, avec la collaboration d'Emmanuel BURY,

Bossuet

Paris, PUPS, 2008, 268 p., $21 \mathrm{~cm}$ («Colloque de la Sorbonne »), $24 €$.

Xavier Kieft

\section{OpenEdition}

\section{Journals}

Édition électronique

URL : http://journals.openedition.org/rhr/7742

DOI : 10.4000/rhr.7742

ISSN : 2105-2573

Éditeur

Armand Colin

Édition imprimée

Date de publication : 1 mars 2011

Pagination : 130-131

ISBN : 978-2200-92685-4

ISSN : 0035-1423

Référence électronique

Xavier Kieft, « Gérard ferreyrolles, Béatrice guion, Jean-Louis auAntin, avec la collaboration d'Emmanuel BURY, Bossuet », Revue de l'histoire des religions [En ligne], 1 | 2011, mis en ligne le 30 mai 2011, consulté le 09 octobre 2020. URL : http://journals.openedition.org/rhr/7742 ; DOI : https://doi.org/10.4000/rhr. 7742

Ce document a été généré automatiquement le 9 octobre 2020.

Tous droits réservés 


\title{
Gérard FERREYROLLES, Béatrice GUION, Jean-Louis QUANTIN, avec la collaboration d'Emmanuel BURY, Bossuet
}

Paris, PUPS, 2008, 268 p., $21 \mathrm{~cm}$ («Colloque de la Sorbonne »), $24 €$.

\author{
Xavier Kieft
}

\section{RÉFÉRENCE}

Gérard FERREYROLLES, Béatrice GUION, Jean-Louis QUANTIN, avec la collaboration

d'Emmanuel BURY, Bossuet, Paris, PUPS, 2008, 268 p., $21 \mathrm{~cm}$ (« Colloque de la

Sorbonne »), $24 €$.

1 Ce petit volume, issu des travaux relatifs au cours public de 2004 de la Société d'étude du XVII siècle, affiche une ambition en apparence modeste : «servir d'introduction à la lecture de Bossuet ». Faute de rivaux crédibles - la quatrième page de couverture ne rappelle-t-elle pas que ce livre constitue «la première synthèse sur Bossuet depuis quarante ans»? - on se doute que cet ouvrage collectif atteindra aisément l'objectif qu'il s'est fixé. Mais cette réussite n'est pas, en fin de compte, ce qu'il convient de souligner ici; ce qui importe est la façon dont le projet entrepris est conduit à son terme.

De ce point de vue, ce livre composite, pour l'élaboration duquel chacun des quatre collaborateurs s'est chargé de présenter une perspective spécifique sur l'évêque de Meaux, est exemplaire. L'absence totale de répétitions d'une partie à l'autre, travers pourtant si fréquent dans les travaux collectifs, fait de ce Bossuet un usuel aussi dense que complet : ce que l'on découvre là est à proprement parler un travail commun et non un simple agrégat de textes hétérogènes. 
Il ne s'agit cependant pas de penser que l'unité du projet implique la simplicité du propos, comme si chaque auteur n'était que le prête-nom d'une entité intellectuelle déterminée. Le lecteur a plaisir à découvrir, entre telle ou telle partie du livre, des tensions interprétatives qui, loin de nuire à la cohérence de l'ensemble, est la cause assumée d'une grande part de sa réussite. Comme J.-L. Quantin le précise dans son introduction, où il retrace l'histoire de la grandeur et des infortunes de l'image de Bossuet auprès du public, il ne s'agissait nullement de présenter un Bossuet particulier, fût-il nouveau (cf. p. 22). Ce souci a déterminé les efforts fournis par les contributeurs, qui, chacun dans son domaine, cherchent sans cesse la nuance du propos et la richesse des motifs, qui conviennent si bien au personnage étudié.

Le péril encouru à tendre en toute occasion à ajuster les positions interprétatives en raison des progrès de la connaissance des textes et de l'histoire du siècle est connu: c'est ainsi que l'on obtient des synthèses ternes et des études oubliées aussitôt qu'on les a lues. On aurait donc facilement pu n'obtenir qu'un ouvrage secondaire voué à l'arbitrage des lectures précédentes, sans élan et sans apport propre. Il n'en est rien. Et force est de constater que l'évêque présenté ici, ce régulier qui doit tant à son siècle, pour tiraillé qu'il semble constamment entre deux tendances contraires, telles la rigueur doctrinale et l'ambition, ne perd nullement en profondeur ce qu'il gagne en complexité.

5 Mais, qu'il s'agisse de l'homme public présenté par J.-L. Quantin, de l'historien dont l'importance est justement rappelée par B.Guion, du politicien évoqué par G. Ferreyrolles ou de l'orateur salué par E. Bury, Bossuet retrouve aujourd'hui l'étoffe d'un personnage et d'un écrivain majeurs, dont l'injustice de l'oubli appelle à être réparée sans tarder. Telle est du reste la clé du succès du livre: plus qu'une introduction, il constitue une invitation à la (re-) lecture de l'auteur du Discours sur l'Histoire universelle. Nul ne doute, donc, qu'en plus de parvenir aisément au but explicite qu'il s'est fixé, ce Bossuet restera vraisemblablement assez longtemps un ouvrage de référence - ce en quoi il ne déméritera pas, car il ne manquera pas d'en inspirer quelques autres.

\section{AUTEURS}

\section{XAVIER KIEFT}

Université Paris-IV (Sorbonne). 